\title{
MAPK inhibitors differentially affect gallic acid-induced human pulmonary fibroblast cell growth inhibition
}

\author{
WOO HYUN PARK \\ Department of Physiology, Institute for Medical Sciences, Chonbuk National University \\ Medical School, Jeonju 561-180, Korea
}

Received July 9, 2010; Accepted September 1, 2010

DOI: $10.3892 / \mathrm{mmr} .2010 .361$

\begin{abstract}
Gallic acid (GA) has various biological properties, including an anti-cancer effect. However, little is known about the toxicological effect of GA in primary normal cells in relation to mitogen-activated protein kinase (MAPK) signaling. In this study, we investigated the effects of MAPK (MEK, JNK or p38) inhibitors on GA-treated human pulmonary fibroblast (HPF) cells in relation to cell growth inhibition, cell death, reactive oxygen species (ROS) and glutathione (GSH). GA induced HPF cell growth inhibition and cell death at $24 \mathrm{~h}$, which was accompanied by the loss of mitochondrial membrane potential (MMP; $\Delta \Psi_{\mathrm{m}}$ ). GA increased ROS levels and GSH-depleted cell numbers in the HPF cells. The MEK inhibitor did not affect cell growth inhibition, cell death, ROS and GSH levels in the GA-treated HPF cells. The JNK inhibitor slightly enhanced cell growth inhibition by GA, while the p38 inhibitor significantly prevented the growth inhibition. Both JNK and p38 inhibitors did not affect cell death, ROS and GSH levels in the GA-treated HPF cells. In conclusion, MAPK inhibitors differentially affected the growth inhibition of GA-treated HPF cells, which were not related to cell death, ROS and GSH levels.
\end{abstract}

Correspondence to: Dr Woo Hyun Park, Department of Physiology, Chonbuk National University Medical School, Jeonju 561-180, Korea

E-mail: parkwh71@chonbuk.ac.kr

Abbreviations: GA, gallic acid; HPF, human pulmonary fibroblast, ROS, reactive oxygen species; MAPK, mitogen-activated protein kinase; MEK, MAP kinase or ERK kinase; ERK, extracellular signalregulated kinase; JNK, c-Jun N-terminal kinase; SOD, superoxide dismutase; MMP $\left(\Delta \Psi_{\mathrm{m}}\right)$, mitochondrial membrane potential; FBS, fetal bovine serum; FITC, fluorescein isothiocyanate; $\mathrm{H}_{2}$ DCFDA, 2',7'-dichlorodihydrofluorescein diacetate; DHE, dihydroethidium; GSH, glutathione; CMFDA, 5-chloromethylfluorescein diacetate; MTT,3-(4,5-dimethylthiazol-2-yl)-2,5-diphenyltetrazolium bromide; PI, propidium iodide

Key words: gallic acid, cell death, human pulmonary fibroblast cells, mitogen-activated protein kinase, reactive oxygen species

\section{Introduction}

Gallic acid (GA) as a polyhydroxylphenolic compound is commonly distributed in various plants, fruits and foods (1) and is very well absorbed in humans (2). Its various biological activities, such as anti-bacterial (3), anti-viral (4) and anti-inflammatory (5), have been reported, and the anti-cancer activity of GA has been reported in various types of cancer cells, such as prostate (6), lung (7,8), gastric, colon, breast, cervical and esophageal (9). Cell death induced by GA is associated with oxidative stress derived from reactive oxygen species (ROS), mitochondrial dysfunction and an increase in intracellular $\mathrm{Ca}^{2+}$ level $(10,11)$.

The mitogen-activated protein kinases (MAPKs) are involved in cell proliferation, differentiation and cell death (12). Substantial evidence demonstrates that the c-Jun N-terminal kinase/stress-activated protein kinase (JNK/SAPK) and p38 are activated by ROS, and oxidative stress leads to apoptosis (13-15). ROS also are known to regulate the activation of the extracellular signal regulated kinase (ERK1/2)-activating kinase (MEK) and ERK (16,17). In most instances, MEK and ERK activation have a pro-survival function, rather than pro-apoptotic effects (18). Different ROS levels and diverse functions of MAPKs by ROS may have opposite effects, even in the same type of cell. Therefore, the relationship between ROS and MAPKs in view of cell survival or cell death signaling requires further clarification.

Recently, we demonstrated that GA reduced the growth of Calu-6 and A549 lung cancer cells (19). In addition, GA inhibited the growth of human pulmonary fibroblast (HPF) normal cells with an $\mathrm{IC}_{50}$ of approximately $400 \mu \mathrm{M}$ at $24 \mathrm{~h}$ (unpublished data). The susceptibility of HPF cells to GA is lower than that of Calu-6 and A549 cancer cells. Furthermore, MEK inhibitor prevented growth inhibition and death in GA-treated Calu-6 cells (unpublished data). However, little is known about the relationships between GA and MAPK inhibitors in normal cells in relation to ROS and GSH levels. Therefore, in the present study we investigated the effects of MAPK inhibitors on cell growth, death, ROS and GSH levels in GA-treated normal HPF cells.

\section{Materials and methods}

Cell culture. HPF cells (PromoCell GmbH, Heidelberg, Germany) were maintained in a humidified incubator 
containing $5 \% \mathrm{CO}_{2}$ at $37^{\circ} \mathrm{C}$. $\mathrm{HPF}$ cells were cultured in complete fibroblast growth medium 2 (PromoCell $\mathrm{GmbH}$ ). They were washed and detached with HepesBSS $(30 \mathrm{mM}$ HEPES), trypsin-EDTA and trypsin neutralization solution (PromoCell GmbH). HPF cells were used between passages four and eight.

Reagents. GA purchased from the Sigma-Aldrich Chemical Company (St. Louis, MO, USA) was dissolved in ethanol at $200 \mathrm{mM}$ as a stock solution. MEK (PD98059), JNK (SP600125) and p38 inhibitors (SB203580) obtained from Calbiochem (San Diego, CA, USA) were dissolved in DMSO at $10 \mathrm{mM}$ as a stock solution. Cells were pre-treated with each MAPK inhibitor for $1 \mathrm{~h}$ before GA treatment. Based on a previous experiment (20), $10 \mu \mathrm{M}$ of each MAPK inhibitor was used as an optimal dose in this experiment. Ethanol $(0.2 \%)$ and DMSO (0.3\%) were used as a control vehicle. All stock solutions were wrapped in foil and kept at $-20^{\circ} \mathrm{C}$.

Cell growth assay. The cell growth inhibition effects by drugs were determined by measuring the 3-(4,5-dimethylthiazol-2yl)-2,5-diphenyltetrazolium bromide (MTT; Sigma-Aldrich Chemical Company) dye absorbance by living cells, as previously described (21). In brief, $3 \times 10^{4}$ cells/well were seeded in 96-well microtiter plates for the MTT assays. After exposure to $400 \mu \mathrm{M} \mathrm{GA}$ and/or a given MAPK inhibitor for $24 \mathrm{~h}, 20 \mu \mathrm{l}$ of MTT solution ( $2 \mathrm{mg} / \mathrm{ml}$ in PBS) was added to each well of 96-well plates (Nunc, Roskilde, Denmark). The plates were incubated for an additional $4 \mathrm{~h}$ at $37^{\circ} \mathrm{C}$. Medium in the plates was withdrawn using pipetting, and $200 \mu 1$ DMSO was added to each well to solubilize the formazan crystals. Optical density was measured at $570 \mathrm{~nm}$ using a microplate reader (Spectra MAX 340; Molecular Devices Co., Sunnyvale, CA, USA).

Annexin V staining for cell death detection. Apoptosis was determined by staining cells with Annexin V-fluorescein isothiocyanate (FITC; Pharmingen, San Diego, CA, USA; Ex/ $\mathrm{Em}=488 / 519 \mathrm{~nm}$ ) and propidium iodide (PI; Sigma-Aldrich Chemical Co.; $\mathrm{Ex} / \mathrm{Em}=488 / 617 \mathrm{~nm}$ ). In brief, $1 \times 10^{6}$ cells in a 60-mm culture dish (Nunc) were incubated with $400 \mu \mathrm{M}$ GA and/or a given MAPK inhibitor for $24 \mathrm{~h}$. Cells were washed twice with cold PBS and then resuspended in $500 \mu \mathrm{l}$ of binding buffer $(10 \mathrm{mM}$ HEPES/NaOH pH 7.4, $140 \mathrm{mM} \mathrm{NaCl}$ and $2.5 \mathrm{mM} \mathrm{CaCl}$ ) at a concentration of $1 \times 10^{6}$ cells $/ \mathrm{ml}$. Annexin V-FITC $(5 \mu \mathrm{l})$ and PI $(1 \mu \mathrm{g} / \mathrm{ml})$ were then added to these cells, which were analyzed with a FACStar flow cytometer (Becton Dickinson).

Measurement of MMP $\left(\Delta \Psi_{m}\right)$. MMP $\left(\Delta \Psi_{\mathrm{m}}\right)$ levels were measured using rhodamine 123 fluorescent dye (SigmaAldrich Chemical Company; Ex/Em = 485/535 nm), as previously described (22). In brief, $1 \times 10^{6}$ cells in a $60-\mathrm{mm}$ culture dish (Nunc) were incubated with $400 \mu \mathrm{M} \mathrm{GA}$ and/or a given MAPK inhibitor for $24 \mathrm{~h}$. Cells were washed twice with PBS and incubated with rhodamine $123(0.1 \mu \mathrm{g} / \mathrm{ml})$ at $37^{\circ} \mathrm{C}$ for $30 \mathrm{~min}$. Rhodamine 123 staining intensity was determined by flow cytometry. An absence of rhodamine 123 from the cells indicated the loss of MMP $\left(\Delta \Psi_{\mathrm{m}}\right)$ in the HPF cells.

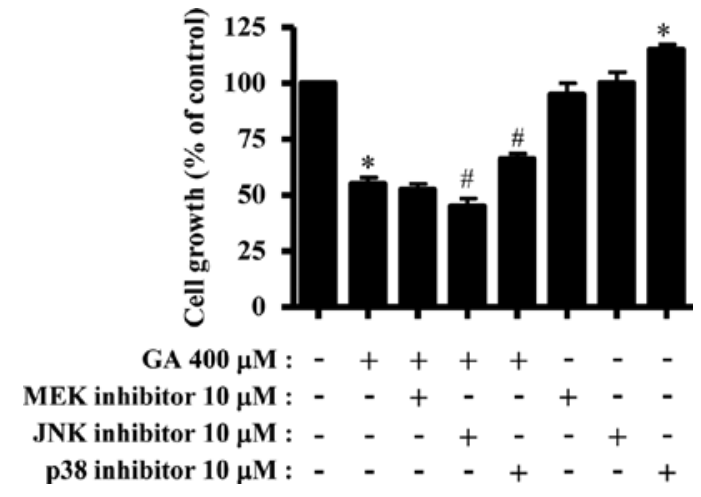

Figure 1. Effects of MAPK inhibitors on cell growth in GA-treated HPF cells. Exponentially growing cells were treated with $400 \mu \mathrm{M}$ GA for $24 \mathrm{~h}$, following $1 \mathrm{~h}$ pre-incubation of $10 \mu \mathrm{M}$ MEK, JNK or p38 inhibitor. The graph shows cellular growth changes in HPF cells at $24 \mathrm{~h}$, as assessed by an MTT assay. "p $<0.05$ compared to the control group. ${ }^{\#} \mathrm{p}<0.05$ compared to cells treated with GA only.

Detection of intracellular $\mathrm{ROS}$ and $\mathrm{O}_{2--}$ levels. Intracellular ROS were detected by means of an oxidation-sensitive fluorescent probe dye, 2',7'-dichlorodihydrofluorescein diacetate $\left(\mathrm{H}_{2} \mathrm{DCFDA}\right.$; Invitrogen Molecular Probes, OR, USA; Ex/ $\mathrm{Em}=495 / 529 \mathrm{~nm})(23)$. As $\mathrm{H}_{2}$ DCFDA is poorly selective for $\mathrm{O}_{2}{ }^{-}$, dihydroethidium (DHE; Invitrogen Molecular Probes; $\mathrm{Ex} / \mathrm{Em}=518 / 605 \mathrm{~nm}$ ), which is highly selective for $\mathrm{O}_{2}^{--}$, was used for its detection. In brief, $1 \times 10^{6}$ cells in a $60-\mathrm{mm}$ culture dish (Nunc) were incubated with $400 \mu \mathrm{M}$ GA and/or a given MAPK inhibitor for $24 \mathrm{~h}$. Cells were then washed in PBS and incubated with $20 \mu \mathrm{M} \mathrm{H}_{2}$ DCFDA or DHE at $37^{\circ} \mathrm{C}$ for $30 \mathrm{~min}$. DCF and DHE fluorescences were detected using a FACStar flow cytometer (Becton Dickinson). ROS and $\mathrm{O}_{2}{ }^{-}$levels were expressed as mean fluorescence intensity (MFI), which was calculated by CellQuest software (Becton Dickinson).

Detection of intracellular glutathione (GSH). Cellular GSH levels were analyzed using 5-chloromethylfluorescein diacetate (CMFDA; Invitrogen Molecular Probes; Ex/Em = $522 / 595 \mathrm{~nm}$ ), as previously described (23). In brief, $1 \times 10^{6}$ cells in a 60-mm culture dish (Nunc) were incubated with $400 \mu \mathrm{M}$ GA and/or a given MAPK inhibitor for $24 \mathrm{~h}$. Cells were then washed with PBS and incubated with $5 \mu \mathrm{M} \mathrm{CMFDA}$ at $37^{\circ} \mathrm{C}$ for $30 \mathrm{~min}$. CMF fluorescence intensity was determined using a FACStar flow cytometer. Negative CMF-stained (GSH-depleted) cells were expressed as a percentage of (-) CMF cells.

Statistical analysis. The results were represented as the mean of at least three independent experiments (mean $\pm \mathrm{SD}$ ). The data were analyzed using Instat software (GraphPad Prism4, San Diego, CA, USA). The Student's t-test or one-way analysis of variance (ANOVA) with post hoc analysis using Tukey's multiple comparison test were used for parametric data. Statistical significance was defined as $\mathrm{p}<0.05$.

\section{Results}

Effects of MAPK inhibitors on cell growth in GA-treated HPF cells. We examined the effect of MAPK inhibitors on the 
A
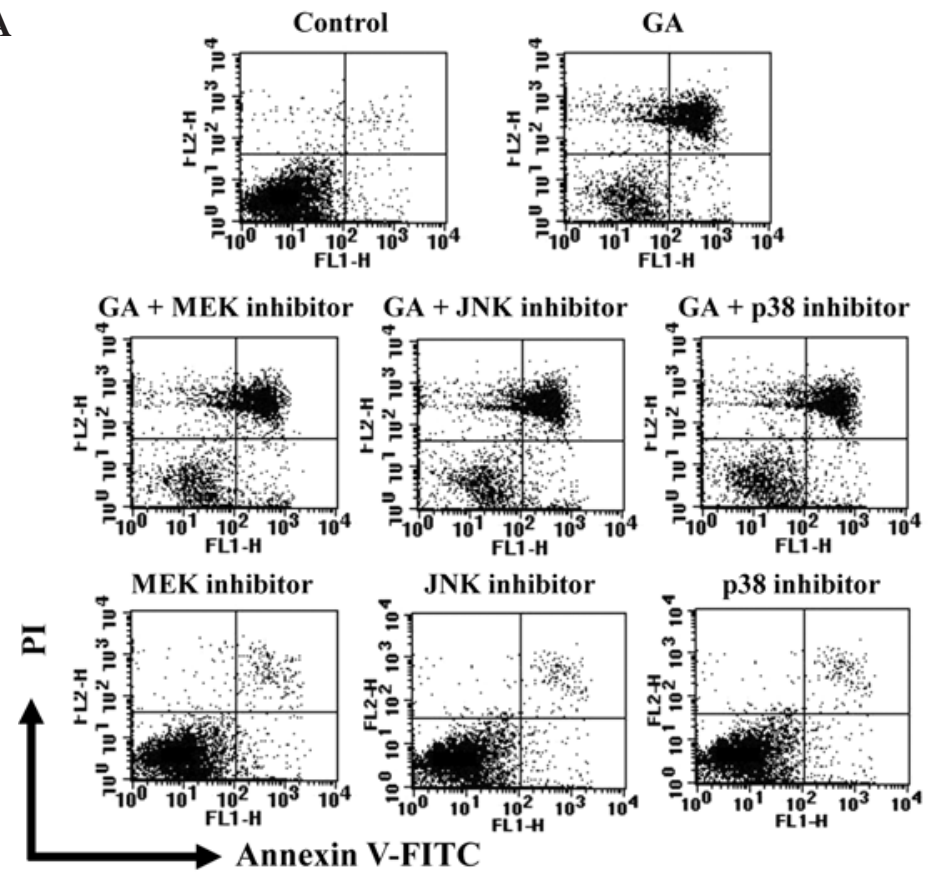

B

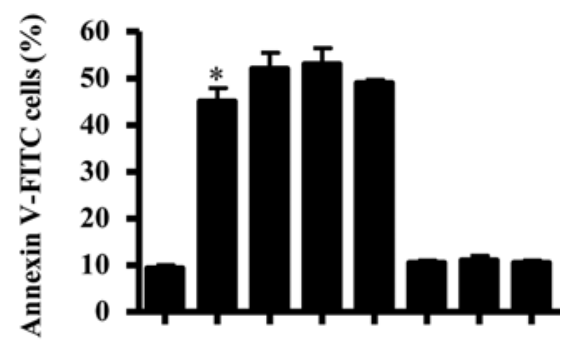

C

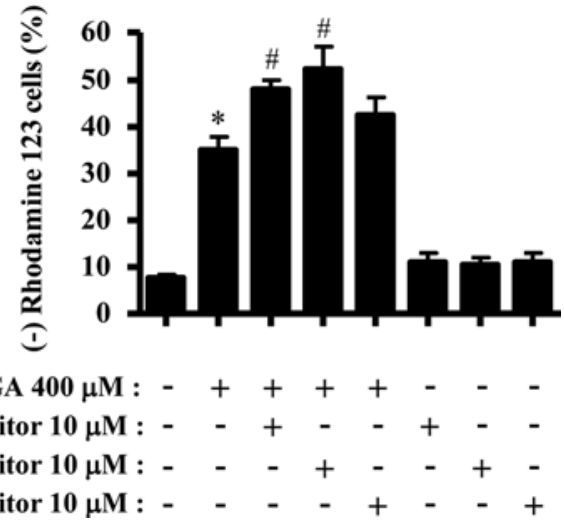

Figure 2. Effects of MAPK inhibitors on cell death and MMP $\left(\Delta \Psi_{\mathrm{m}}\right)$ in GA-treated HPF cells. Exponentially growing cells were treated with $400 \mu \mathrm{M}$ GA for $24 \mathrm{~h}$, following a 1-h pre-incubation with $10 \mu \mathrm{M}$ MEK, JNK or p38 inhibitor. Annexin V-FITC/PI staining and MMP $\left(\Delta \Psi_{\mathrm{m}}\right)$ in HPF cells were measured with a FACStar flow cytometer. (A) Each figure shows representatives for Annexin V-FITC/PI-stained cells. (B) Graph shows the percentages of Annexin V-positive-stained cells from A. (C) Graph shows the percentages of rhodamine 123-negative [MMP $\left(\Delta \Psi_{\mathrm{m}}\right)$ loss] cells. " $\mathrm{p}<0.05$ compared to the control group. ${ }^{\#} \mathrm{p}<0.05$ compared to cells treated with GA only.

growth of GA-treated HPF cells. Treatment with $400 \mu \mathrm{M} \mathrm{GA}$ used in this study inhibited the growth of HPF cells by $\sim 50 \%$ at $24 \mathrm{~h}$ (Fig. 1). The MEK inhibitor did not affect the growth inhibition by GA. While the JNK inhibitor slightly enhanced the growth inhibition of GA, the p38 inhibitor significantly prevented the growth inhibition. Treatment with the p38 inhibitor alone increased HPF control cell growth (Fig. 1).

Effects of MAPK inhibitors on cell death and $M M P\left(\Delta \Psi_{m}\right)$ in GA-treated HPF cells. GA significantly induced cell death in HPF cells, as evidenced by Annexin V-stained cells (Fig. 2A and B). The MEK and JNK inhibitors slightly increased the number of Annexin V-stained cells in the GA-treated HPF cells. None of the MAPK inhibitors alone affected the numbers of Annexin V-stained HPF control cells (Fig. 2A and $\mathrm{B})$.

In addition, GA significantly triggered the loss of MMP $\left(\Delta \Psi_{\mathrm{m}}\right)$ in the HPF cells (Fig. 2C). The MEK and JNK inhibitors significantly intensified MMP $\left(\Delta \Psi_{\mathrm{m}}\right)$ loss in the GA-treated HPF cells. None of the MAPK inhibitors alone influenced the loss of MMP $\left(\Delta \Psi_{\mathrm{m}}\right)$ level in the HPF control cells (Fig. 2C).

Effects of MAPK inhibitors on ROS and GSH levels in the GA-treated HPF cells. We determined whether intracellular ROS and GSH levels in GA-treated HPF cells were altered by each MAPK inhibitor. The ROS (DCF) level, such as $\mathrm{H}_{2} \mathrm{O}_{2}$, was increased in the GA-treated HPF cells (Fig. 3A and B). None of the MAPK inhibitors significantly altered ROS levels in the GA-treated HPF cells. Only the p38 inhibitor alone increased the ROS level in the HPF control cells (Fig. 3A and
B). Red fluorescence derived from DHE reflecting intracellular $\mathrm{O}_{2}{ }^{--}$level was also increased in the HPF cells (Fig. 3C). None of the MAPK inhibitors altered the $\mathrm{O}_{2}{ }^{--}$levels in the GA-treated HPF cells. The p38 inhibitor also increased the $\mathrm{O}_{2}{ }^{-}$level in the HPF control cells (Fig. 3C).

GA increased the number of GSH-depleted cells in the HPF cells (Fig. 4A and B). None of the MAPK inhibitors significantly altered the GSH-depleted cell number in the GA-treated HPF or HPF control cells.

\section{Discussion}

In the present study, we focused on evaluating the effects of MAPK inhibitors on GA-treated normal HPF cells in relation to cell death, ROS and GSH, since we observed that GA induced the growth inhibition and death of HPF cells.

ERK activation has a pro-survival function rather than pro-apoptotic effects $(18,24)$. According to our result, the MEK inhibitor, which presumably decreases ERK activity, did not significantly affect cell growth inhibition and cell death by GA. In addition, the MEK inhibitor alone did not alter HPF growth and death. These results suggested that the inhibition of ERK signaling by the MEK inhibitor was not involved in growth and death in GA-treated or GA-untreated HPF cells. However, we observed that the MEK inhibitor slightly reduced cell death in GA-treated Calu-6 lung cancer cells, whereas it enhanced that in GA-treated A549 lung cancer cells (unpublished data). Therefore, the anti- or pro-apoptotic effects of the MEK inhibitor on GA-treated lung cells can be variable depending on cell type. 
A
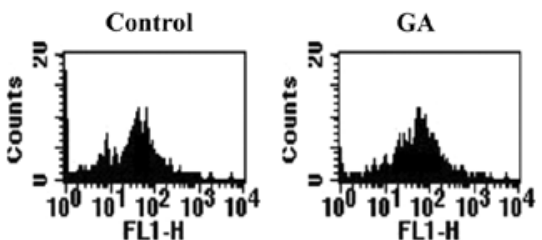

GA + MEK inhibitor GA + JNK inhibitor GA + p38 inhibitor
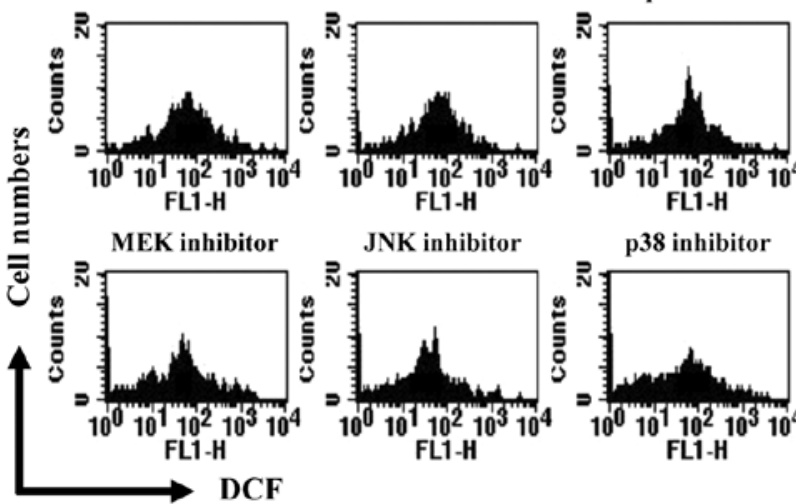

B

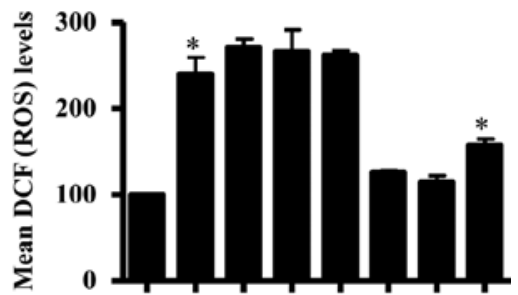

C

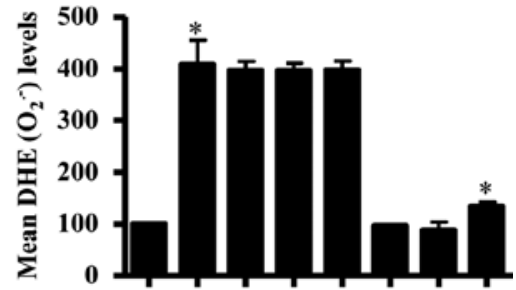

GA $400 \mu \mathrm{M}:-++++-\quad-$

MEK inhibitor $10 \mu \mathrm{M}:--+--+-$

JNK inhibitor $10 \mu \mathrm{M}:-\quad-\quad+\quad-\quad-\quad+-$

p38 inhibitor $10 \mu \mathrm{M}$ : - $\quad-\quad-\quad+\quad-\quad+$

Figure 3. Effects of MAPK inhibitors on ROS levels in GA-treated HPF cells. Exponentially growing cells were treated with $400 \mu \mathrm{M}$ GA for 24 h, following a 1-h pre-incubation with $10 \mu \mathrm{M}$ MEK, JNK or p38 inhibitor. ROS levels in HPF cells were measured using a FACStar flow cytometer. (A) Each histogram as a representative indicates the DCF levels in each cell group. (B and C) Graphs indicate DCF (ROS) levels (\%) compared to GA-untreated control cells from A (B) and DHE $\left(\mathrm{O}_{2} \cdot{ }^{-}\right)$levels (\%) compared to GA-untreated control cells (C). " $\mathrm{p}<0.05$ compared to the control group.

A

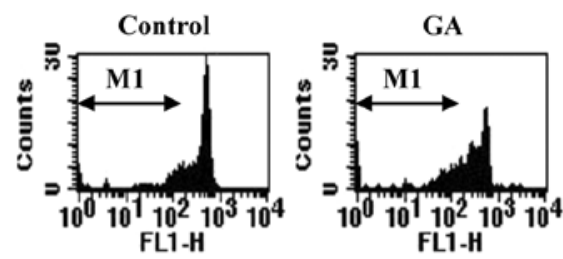

GA + MEK inhibitor GA + JNK inhibitor GA + p38 inhibitor
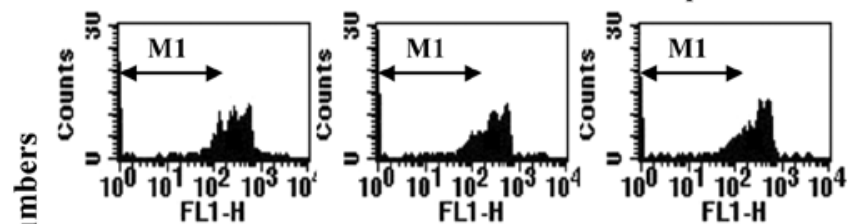

$\stackrel{\Xi}{\bar{J}}$

MEK inhibitor
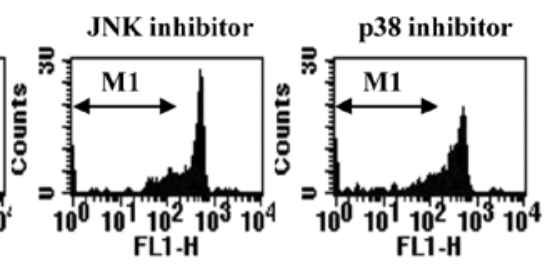

CMF
B

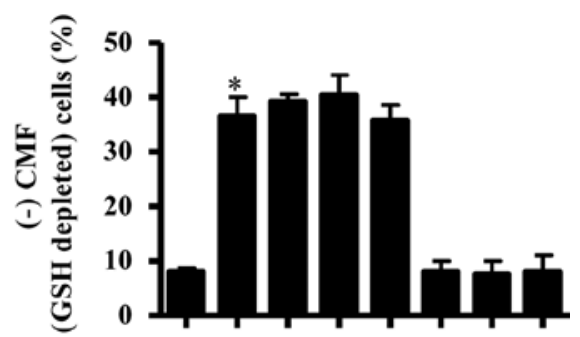

GA $400 \mu \mathrm{M}:-++++-\quad-$

MEK inhibitor $10 \mu \mathrm{M}:--+--+-$

JNK inhibitor $10 \mu \mathrm{M}:-\quad-\quad+-\quad+\quad-$

p38 inhibitor $10 \mu \mathrm{M}$ : - $-\quad-\quad+-\quad-+$

Figure 4. Effects of MAPK inhibitors on GSH levels in GA-treated HPF cells. Exponentially growing cells were treated with $400 \mu \mathrm{M}$ GA for $24 \mathrm{~h}$, following a 1-h pre-incubation with $10 \mu \mathrm{M}$ MEK, JNK or p38 inhibitor. GSH levels in HPF cells were measured using a FACStar flow cytometer. (A) Each histogram as a representative shows CMF intensities in the cells. M1 indicates (-) CMF (GSH-depleted) cells. (B) Graph shows the percentages of (-) CMF (GSH-depleted) cells (M1 region in A). * $\mathrm{p}<0.05$ compared to the control group.
In general, the activation of JNK or p38 leads to apoptosis (13-15). In fact, the JNK inhibitor was found to protect PC12 rat phenochromocytoma against GA-induced cell death (25), and the p38 inhibitor was found to decrease the death of pyrogallol-induced calf pulmonary artery endothelial cells (20). However, in the present study, the JNK or p38 inhibitor did not significantly alter cell death in the GA-treated or -untreated HPF cells. In particular, the JNK inhibitor intensified the cell growth inhibition of GA, whereas the p38 inhibitor significantly prevented this inhibition. The p38 inhibitor also increased the growth of HPF control cells.

These results in some way suggest that the inhibition of JNK or p38 signaling by each inhibitor is not related to HPF cell death, but to its cell growth inhibition. By contrast, the JNK inhibitor was found to partially reduce the growth inhibition of Calu- 6 cells by GA, whereas the p38 inhibitor mildly enhanced the cell growth inhibition (unpublished data). These results imply that JNK and p38 inhibitors appear to differentially affect the growth inhibition of normal or cancer cells 
by GA. In relation to MMP $\left(\Delta \Psi_{\mathrm{m}}\right)$, MEK and JNK inhibitors significantly intensified MMP $\left(\Delta \Psi_{\mathrm{m}}\right)$ loss in GA-treated HPF cells. These data imply that both inhibitors are involved in MMP $\left(\Delta \Psi_{\mathrm{m}}\right)$ loss in GA-treated HPF cells, rather than GA-induced HPF cell death.

Increasing evidence suggests that apoptosis induced by GA is associated with oxidative stresses derived from ROS (11,26). Similarly, ROS levels, including $\mathrm{O}_{2}{ }^{--}$, were significantly increased in GA-treated HPF cells. None of the MAPK inhibitors significantly altered ROS levels in the GA-treated HPF cells. Only the p38 inhibitor alone significantly modified ROS levels in the HPF control cells without the induction of cell death. These data suggest that MAPK inhibitors do not influence ROS levels in GA-treated HPF cells, and the ROS increase in p38 inhibitor-treated HPF cells are not involved in HPF cell death. GSH, as a main non-protein antioxidant, eliminates the $\mathrm{O}_{2}{ }^{--}$and provides electrons for enzymes, such as GSH peroxidase, which reduce $\mathrm{H}_{2} \mathrm{O}_{2}$ to $\mathrm{H}_{2} \mathrm{O}$. It has been reported that apoptotic effects are inversely comparative to GSH content $(27,28)$. Likewise, GA increased the number of GSH-depleted cells in the HPF cells. MAPK inhibitors showing a non-effect on GA-induced HPF cell death did not significantly alter the GSH-depleted cell numbers. Therefore, our results support the notion that the intracellular GSH level has a decisive effect on anti-cancer drug-induced apoptosis.

Conclusively, MAPK inhibitors differentially affect the growth inhibition of GA-treated HPF cells, and this effect is not related to cell death, ROS and GSH levels.

\section{Acknowledgements}

This study was supported by the Basic Science Research Program through the National Research Foundation of Korea (NRF) funded by the Ministry of Education, Science and Technology (2010-0007059).

\section{References}

1. Niemetz R and Gross GG: Enzymology of gallotannin and ellagitannin biosynthesis. Phytochemistry 66: 2001-2011, 2005.

2. Shahrzad S, Aoyagi K, Winter A, Koyama A and Bitsch I: Pharmacokinetics of gallic acid and its relative bioavailability from tea in healthy humans. J Nutr 131: 1207-1210, 2001.

3. Kang MS, Oh JS, Kang IC, Hong SJ and Choi CH: Inhibitory effect of methyl gallate and gallic acid on oral bacteria. J Microbiol 46: 744-750, 2008.

4. Kratz JM, Andrighetti-Frohner CR, Leal PC, et al: Evaluation of anti-HSV-2 activity of gallic acid and pentyl gallate. Biol Pharm Bull 31: 903-907, 2008.

5. Kim SH, Jun CD, Suk K, et al: Gallic acid inhibits histamine release and pro-inflammatory cytokine production in mast cells. Toxicol Sci 91: 123-131, 2006.

6. Kaur M, Velmurugan B, Rajamanickam S, Agarwal R and Agarwal C: Gallic acid, an active constituent of grape seed extract, exhibits anti-proliferative, pro-apoptotic and anti-tumorigenic effects against prostate carcinoma xenograft growth in nude mice. Pharm Res 26: 2133-2140, 2009.

7. Kawada M, Ohno Y, Ri Y, et al: Anti-tumor effect of gallic acid on LL-2 lung cancer cells transplanted in mice. Anticancer Drugs 12: 847-852, 2001.

8. Ohno Y, Fukuda K, Takemura G, et al: Induction of apoptosis by gallic acid in lung cancer cells. Anticancer Drugs 10: 845-851, 1999.
9. Faried A, Kurnia D, Faried LS, Usman N, Miyazaki T, Kato H and Kuwano H: Anticancer effects of gallic acid isolated from Indonesian herbal medicine, Phaleria macrocarpa (Scheff.) Boerl, on human cancer cell lines. Int J Oncol 30: 605-613, 2007.

10. Chen HM, Wu YC, Chia YC, Chang FR, Hsu HK, Hsieh YC, Chen CC and Yuan SS: Gallic acid, a major component of Toona sinensis leaf extracts, contains a ROS-mediated anti-cancer activity in human prostate cancer cells. Cancer Lett 286: 161-171, 2009.

11. Inoue M, Sakaguchi N, Isuzugawa K, Tani H and Ogihara Y: Role of reactive oxygen species in gallic acid-induced apoptosis. Biol Pharm Bull 23: 1153-1157, 2000.

12. Blenis J: Signal transduction via the MAP kinases: proceed at your own RSK. Proc Natl Acad Sci USA 90: 5889-5892, 1993.

13. Hsin YH, Chen CF, Huang S, Shih TS, Lai PS and Chueh PJ: The apoptotic effect of nanosilver is mediated by a ROS- and JNK-dependent mechanism involving the mitochondrial pathway in NIH3T3 cells. Toxicol Lett 179: 130-139, 2008.

14. Mao X, Yu CR, Li WH and Li WX: Induction of apoptosis by shikonin through a ROS/JNK-mediated process in $\mathrm{Bcr} /$ Abl-positive chronic myelogenous leukemia (CML) cells. Cell Res 18: 879-888, 2008.

15. Gomez-Lazaro M, Galindo MF, Melero-Fernandez de Mera RM, et al: Reactive oxygen species and $\mathrm{p} 38$ mitogen-activated protein kinase activate Bax to induce mitochondrial cytochrome c release and apoptosis in response to malonate. Mol Pharmacol 71: 736-743, 2007.

16. Guyton KZ, Liu Y, Gorospe M, Xu Q and Holbrook NJ: Activation of mitogen-activated protein kinase by $\mathrm{H}_{2} \mathrm{O}_{2}$. Role in cell survival following oxidant injury. J Biol Chem 271: 4138-4142, 1996.

17. Liu Y, Borchert GL, Surazynski A, Hu CA and Phang JM: Proline oxidase activates both intrinsic and extrinsic pathways for apoptosis: the role of ROS/superoxides, NFAT and MEK/ ERK signaling. Oncogene 25: 5640-5647, 2006.

18. Henson ES and Gibson SB: Surviving cell death through epidermal growth factor (EGF) signal transduction pathways: implications for cancer therapy. Cell Signal 18: 2089-2097, 2006.

19. You BR and Park WH: Gallic acid-induced lung cancer cell death is related to glutathione depletion as well as reactive oxygen species increase. Toxicol In Vitro 24: 1356-1362, 2010.

20. Han YH, Moon HJ, You BR, Kim SZ, Kim SH and Park WH: JNK and p38 inhibitors increase and decrease apoptosis, respectively, in pyrogallol-treated calf pulmonary arterial endothelial cells. Int J Mol Med 24: 717-722, 2009.

21. Park WH, Seol JG, Kim ES, Hyun JM, Jung CW, Lee CC, Kim BK and Lee YY: Arsenic trioxide-mediated growth inhibition in MC/CAR myeloma cells via cell cycle arrest in association with induction of cyclin-dependent kinase inhibitor, p21, and apoptosis. Cancer Res 60: 3065-3071, 2000.

22. Han YH, Kim SZ, Kim SH and Park WH: Arsenic trioxide inhibits growth of As4.1 juxtaglomerular cells via cell cycle arrest and caspase-independent apoptosis. Am J Physiol Renal Physiol 293: F511-F520, 2007.

23. Han YH, Kim SZ, Kim SH and Park WH: Pyrogallol as a glutathione depletor induces apoptosis in HeLa cells. Int $\mathrm{J}$ Mol Med 21: 721-730, 2008.

24. Rygiel TP, Mertens AE, Strumane K, van der Kammen R and Collard JG: The Rac activator Tiam1 prevents keratinocyte apoptosis by controlling ROS-mediated ERK phosphorylation. J Cell Sci 121: 1183-1192, 2008.

25. Kang MK, Kang NJ, Jang YJ, Lee KW and Lee HJ: Gallic acid induces neuronal cell death through activation of c-Jun N-terminal kinase and downregulation of Bcl-2. Ann NY Acad Sci 1171: 514-520, 2009.

26. Serrano A, Palacios C, Roy G, Cespon C, Villar ML, Nocito M and Gonzalez-Porque P: Derivatives of gallic acid induce apoptosis in tumoral cell lines and inhibit lymphocyte proliferation. Arch Biochem Biophys 350: 49-54, 1998.

27. Poot M, Teubert H, Rabinovitch PS and Kavanagh TJ: De novo synthesis of glutathione is required for both entry into and progression through the cell cycle. J Cell Physiol 163: 555-560, 1995.

28. Schnelldorfer T, Gansauge S, Gansauge F, Schlosser S, Beger HG and Nussler AK: Glutathione depletion causes cell growth inhibition and enhanced apoptosis in pancreatic cancer cells. Cancer 89: 1440-1447, 2000. 